\title{
ANALISIS PENGARUH SIKAP, KONTROL PERILAKU, DAN NORMA SUBJEKTIF TERHADAP PERILAKU SAFETY
}

\author{
ANALYSIS OF EFFECT ATTITUDE, PERCEIVED, AND \\ SUBJECTIVE NORM ON SAFETY BEHAVIOR
}

\author{
Gilang Dwi Prakoso ${ }^{1}$ ), Mohammad Zainal Fatah ${ }^{2}$ ) \\ 1,2 Departemen Promosi Kesehatan Dan Ilmu Perilaku, \\ Fakultas Kesehatan Masyarakat, Universitas Airlangga, Surabaya. \\ Email : gilangdwiprakos@gmail.com
}

\begin{abstract}
Safety behavior in the workplace has aims to make the workers get off from work accidents that can cause financial or material losses, disability and death. The workers supposed to work safety so that companies or workplaces get the financial or material benefits. The purpose of this research was to find out the factors that affect workers to work safety. This research was an analytical descriptive with quantitative approach. Data collection was using questionnaires to respondents. The worker's safety behavior which difficult to control when working made the number of workplace accident bigger. To know the factors that influence safety behavior was by connecting attitude, subjective norm, and worker's perceived with safety behavior according to company rules. The results of this study showed that there was a relationship between attitude, perceived, and subjective norm with the worker's safety behavior. This is showed by the use of PPE such as helmet, shoes, and earplug. The important of safety behavior for the worker was to alert the worker of their safety and security when they were working so they not got financial and material loss for the company, disability and death of the workers.
\end{abstract}

Keyword: safety, perceived, subjective norm and attitude

\begin{abstract}
Abstrak: Safety behavior di tempat kerja bertujuan supaya pekerja terhindar dari kecelakaan kerja yang dapat menimbulkan kerugian financial dan material bagi perusahaan, kecacatan dan kematian tenaga kerja. Tenaga kerja diwajibkan untuk berperilaku safety agar perusahaan mendapatkan keuntungan baik dari segi financial dan material. Tujuan dari penelitian ini adalah mencari faktor yang memengaruhi pekerja untuk berperilaku safety. Metode yang digunakan dalam penelitian ini adalah deskriptif analitik dengan pendekatan kuantitatif. Pengumpulan data didapat dengan menggunakan kuesioner. Perilaku safety tenaga kerja yang sulit dikontrol menyebabkan tingginya angka kecelakaan kerja di perusahaan. Untuk mengetahui faktor yang dapat memengaruhi terjadinya safety behavior adalah dengan menghubungkan attitude, subjective norm, dan perceived tenaga kerja dengan perilaku safety sesuai standart perusahaan. Hasil penelitian menunjukkan adanya hubungan antara attitude, perceived dan subjective norm terhadap safety behavior tenaga kerja. Hal ini di buktikan dengan penggunaan APD berupa helm, sepatu, dan earplug. Pentingnya safety behavior saat bekerja di harapkan menyadarkan pekerja akan keselamatan dan keamanan diri mereka saat bekerja agar tidak menimbulkan kerugian financial dan material bagi perusahaan maupun kecacatan dan kematian bagi tenaga kerja.
\end{abstract}

Kata Kunci : aman, kontrol perilaku, norma subjektif dan sikap 


\section{PENDAHULUAN}

\begin{abstract}
Perkembangan zaman membuat kecanggihan teknologi semakin memudahkan manusia dalam kehidupan sehari-hari. Tuntutan dari masyarakat akan teknologi yang dapat mempermudah kegiatan/ pekerjaannya sehari-hari semakin banyak. Perusahaan-perusahan diharuskan memproduksi ratusan hingga ribuan produk demi mencukupi permintaan pasar. Tuntutan ini membuat tekanan diperusahaan dalam hal produksi sangatlah tinggi. Para tenaga kerja di bagian produksi memiliki beban kerja yang sangat tinggi, sehingga risiko terjadinya kecelakaan kerja juga tinggi. Maka dari itu pekerja diharapkan berperilaku safety supaya bekerja secara selamat dan aman dan terhindar dari kecelakaan kerja yang berakibat kecacatan atau kematian (Santoso dan Sherly, 2012).
\end{abstract}

Menurut WHO

menyebutkan bahwa ada 1,3 juta orang setiap tahunnya meninggal karena perilaku unsafety, atau kurang lebih 3000 kematian tiap harinya akibat perilaku unsafety di seluruh dunia. Tingginya angka kecelakaan kerja didunia juga diikuti tingginya angka kecelakaan kerja diIndonesia. Berdasarkan data PT. Jamsostek pada tahun 2007 sampai tahun 2011, bahwa selama tahun 2007 terjadi 83.714 kasus kecelakaan kerja, kemudian pada tahun 2008 terjadi 94.736 kasus kecelakaan kerja. Pada tahun 2009 terjadi kasus kecelakaan kerja sebesar 9.314 kasus, tahun 2010 terjadi 98.711 kasus kecelakaan kerja dan pada tahun 2011 terjadi 99.491 kasus kecelakaan kerja (Retnani, D dan Denny., 2013). Tingginya kasus kecelakan kerja di akibatkan perilaku tenaga kerja yang unsafety saat bekerja.

Tingginya angka kecelakaan kerja di perusahaan membuat pemerintah mengeluarkan peraturan yang wajib dilakukan oleh tenaga kerja saat bekerja (UU No13 Tahun 2013). Karena salah satu aspek yang bisa mencegah terjadinya kecelakaan kerja pada tenaga kerja adalah perilaku tenaga kerja itu sendiri. Bukan hanya pekerja yang wajib, tetapi perusahaan juga wajib menyediakan alat pelindung diri demi keamanan dan keselamatan tenaga kerjanya. Meskipun tenaga kerja sudah memiliki perilaku yang baik terhadap penggunaan APD, tetapi kalau perusahan tidak menyediakan kebutuhan akan keselamatan saat bekerja, tenaga kerja juga tidak akan berperilaku safety dan risiko kecelakaan kerjapun juga akan tetap meningkat.

Kecelakaan kerja merupakan suatu kejadian yang tidak diinginkan, tidak terduga kedatangannya, tidak terkontrol dan tidak diharapkan. kecelakaan kerja dapat mengakibatkan kerugian material ataupun kerugian financial di tempat kerja (De Reamer, 1958). Kecelakaan kerja dapat terjadi karena perilaku dari tenaga kerja yang tidak baik saat bekerja yang dapat menimbulkan risiko kecelakaan kerja yang tinggi. Hal ini sering terjadi karena perilaku tenaga kerja yang kurang mau mematuhi peraturan yang telah dibuat oleh perusahaan.

Perilaku adalah sebuah respon dari diri sendiri terhadap suatu obyek atau benda yang ada disekitarnya (Skinner, 1993 dalam Notoatmodjo, 2014). Seperti halnya dengan tenaga kerja, mereka melakukan suatu perilaku safety di kantor karena adanya suatu obyek/ alat pelindung diri yang mempengaruhi mereka bahwa apabila mereka memakainya mereka akan aman dan selamat sehingga terhindar dari kecelakaan kerja yang dapat membuat kerugian seperti penderitaan fisik (perasaan trauma, cacat, kematian dan rasa bersalah), kerusakan benda seperti mesin produksi, perlengkapan produksi, terjadi keributan dan kepanikan, produksi tidak sesuai target dan lain-lain nya (Depnakertrans, 2003).

Perilaku dalam bekerja dibagi menjadi dua yaitu, perilaku safety dan perilaku unsafety. perilaku safety adalah sebuah perilaku yang mempunyai risiko terjadinya kecelakaan kerja yang sangat rendah, dimana para tenaga kerja sudah menggunakan alat pelindung diri seperti helm safety, sepatu safety, dan earplug. 
Sehingga tenaga kerja dapat bekerja dengan aman dan selamat. Perilaku unsafety adalah suatu perilaku dimana risiko terjadinya kecelakaan kerja pada tenaga kerja sangat tinggi, hal ini dikarenakan tenaga kerja tidak menggunakan alat pelindung diri yang sudah diatur ditempat kerja oleh perusahaan (Ayu, dkk., 2017).

Perubahan perilaku pada tenaga kerja merupakan suatu hal yang sangat sulit dirubah. Perilaku tenaga kerja dipengaruhi oleh niat dari tenaga kerja itu sendiri, karena niat merupakan suatu pemikiran yang nyata dari refleksi rencana untuk menentukan perilaku pada tenaga kerja (Izdihar, H., 2012). Untuk merubah atau mengetahui faktor apa yang dapat membuat perilaku safety pada tenaga kerja maka di gunakan theory of planned behavior.

Theory of Planned Behavior menyebutkan bahwa seseorang dapat melakukan sebuah perilaku apabila mempunyai niat, karena niat membuat seseorang melakukan suatu perilaku. Theory of planned behavior memiliki beberapa faktor yang dapat mempengaruhi peruabahan perilaku pada seseorang atau tenaga kerja, yaitu attitude, subjective norm, dan perceived (Ajzen, I., 2002). Apabila perilaku tenaga kerja tidak dapat dirubah menjadi safety saat bekerja, maka angka kecelakaan kerja di Indonesia akan semakin tinggi tiap tahunnya.
Kecelakaan kerja di Indonesia sampai tahun 2015 masih sangatlah tinggi. Menurut badan penyelenggaraan jaminan sosial atau BPJS, (2015) ada 105. 182 kejadian kecelakaan kerja. Adapun teori mekanisme terjadinya kecelekaan kerja. Menurut Reason (1995\&1997) yaitu mulai dari faktor organisasi, faktor manajerial, faktor individu, active failure, keadaan bahaya, dan kecelakaan. Salah satu perusahaan yang memiliki risiko kecelakan kerja tinggi yaitu PT. Abcd. dengan tingkat kecelakaan kerja paling tinggi pada perilaku penggunaan alat pelindung diri.

Kejadian unsafety behavior di PT. Abcd sangat beragam jenisnya. Sesuai data yang diperoleh dari PT. Abcd ada 4 jenis faktor kecelakaan kerja yaitu posisi tubuh, APD, area kerja dan berkendara dengan masing masing persentase yaitu posisi tubuh $(1,5 \%)$, APD $(23,26 \%)$, area kerja $(0,64 \%)$, dan berkendara $(4,77 \%)$. Dapat dilihat dari persentase setiap faktor yang berisiko, alat pelindung diri merupakan faktor yang paling tinggi berisiko terjadi kecelakaan kerja. Pada alat pelindung diri sering kali terjadi karena perilaku tenaga kerja yang tidak mau menggunakan alat pelindung diri saat bekerja, rata-rata seperti helm safety, sepatu safety, dan earplug. Mereka menganggap hal ini tidak perlu karena sudah kebiasaan tidak memakai. Berikut gambar diagram dari tingkatan faktor terjadinya risiko bahaya di PT. Abcd.

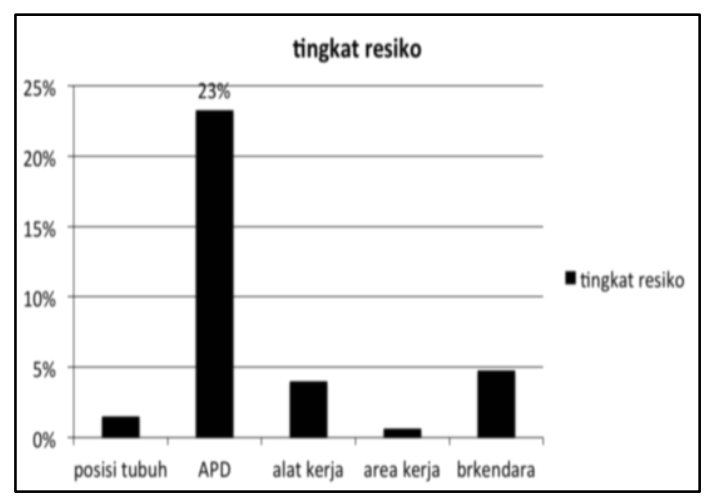

Gambar 1. Persentase faktor risiko kecelakaan kerja di PT. Abcd tahun 2017

Berdasarkan UU No.1 Tahun 1970 tempat kerja ialah suatu tempat dimana terdapat aktivitas. Aktivitas tersebut bisa diruangan terbuka atau 
ruangan tertutup. Di dalam aktivitas tersebut terdapat macam-macam risiko bahaya yang dapat menimbulkan kerugian financial atau kerugian material, bahkan dalam kecelakaan kerja dapat menimbulkan korban jiwa atau kecacatan. Sedangkan menurut Peraturan Menteri Tenaga Kerja dan Transmigrasi No. PER.08/MEN/VII/2010 menyebutkan bahwa tenaga kerja/buruh adalah orang yang diberi upah atau imbalan untuk melakukan suatu kegiatan bagi perusahaan.

Merubah perilaku pada tenaga kerja bisa dilakukan menggunakan theory of planned behavior. Ada beberapa faktor yang dapat mempengaruhi perubahan perilaku pada tenaga kerja, yaitu attitude, subjective norm dan perceived, berikut beberapa faktornya. Faktor dari individu sendiri yang sering kali memberikan risiko terjadinya kecelakaan kerja pada tenaga kerja, seperti sikap tenaga kerja saat bekerja. Terkadang pekerja tidak mengikuti peraturan yang sudah dibuat oleh perusahaan agar pekerja menjadi aman dan selamat saat bekerja. Contohnya seperti perilaku tenaga kerja yang tidak menggunakan alat pelindung diri saat bekerja. Perilaku sendiri dipengaruhi oleh sikap tenaga kerja dalam menggunakan alat pelindung diri. Selain sikap, ada faktor lain dari diri manusia yang dapat meningkatkan risiko unsafety behavior.

Subjective norm merupakan faktor atau variabel lain yang dapat mempengaruhi terjadinya perubahan perilaku pada tenaga kerja. Dukungan dari lingkungan sekitar dapat memepngaruhi tenaga kerja dalam menggunakan alat pelindung diri. Semakin banyak tenaga kerja yang saling mengingatkan ditempat kerja, maka semakin sadar juga tenaga kerja tersebut bahwa alat pelindung diri sangat penting dalam bekerja. Karena masukan masukan dari lingkungan sekitar nantinya akan akan mempengaruhi proses menentukan pilihan bagi tenaga kerja itu sendiri ( Ajzen, I. 2005).

Perceived merupakan keyakinan dari diri tenaga kerja dalam merubah perilakunya yang dipengaruhi oleh tingkat kesulitan dan kemudahan, pengalaman, informasi dan seberapa besar kesempatan yang diberikan kepada tenaga kerja. Salah satu contoh yang terjadi di PT. Abcd adalah pemberian kesempatan pada tenaga kerja dengan menyediakan sarana prasarana, menyediakan alat pelindung diri sesuai dengan jumlah tenaga kerja dan membuat kebijakan.

Beberapa faktor dari theory of planned behavior nantinya akan digunakan sebagai variabel untuk mencari hubungan antara variabel dengan perilaku safety tenaga kerja, yang nantinya akan diketahui faktor apa yang mendorong tenaga kerja untuk merubah perilaku dari unsafety menjadi safety behavior.

Data yang sudah diperoleh dan berdasarkan teori-teori menyebutkan bahwa tingkat risiko terjadinya kecelakaan kerja pada tenaga kerja di PT. Abcd sangatlah tinggi dari hal perilaku penggunaan alat pelindung diri. Nantinya akan dicari faktor apa saja yang membuat tenaga kerja dapat merubah perilakunya dari unsafety menjadi safety memiliki niat safety behavior.

Rumusan masalah dalam penelitian ini adalah "bagaimana pengaruh sikap/ attitude, subjective norm, dan perceived tenaga kerja saat bekerja terhadap unsafety behavior".

\section{METODE}

Penelitian ini menggunakan metode deskriptif analitik dan melakukan pendekatan secara kuantitatif. Tujuan dari dilakukannya penelitian ini adalah untuk menganalisis pengaruh sikap/ attitude, subjective norm, dan perceived tenaga kerja terhadap safety behavior. Penelitian ini meneliti 2 variabel yaitu bebas dan terikat. Variable bebas pada penelitian ini adalah sikap/ attitude, subjective norm dan perceived tenaga kerja. Sedangkan variable terikat pada penelitian ini adalah safety behavior. Variable attitude akan digolongkan menjadi dua golongan yaitu kurang baik dan baik dengan jumlah tenaga kerja sebanyak 79 Varibel subjective norm pada penelitian ini dibagi menjadi dua golongan yaitu kurang baik dan baik. Variabel perceived pada penelitian ini nantinya dibagi menjadi dua golongan yaitu tidak memenuhi dan memenuhi. Penelitian ini menggunakan 
responden tenaga kerja di PT. Abcd, dengan jumlah total tenaga kerja pada PT. Abcd sebanyak 6400 tenaga kerja dan penyebaran dilakukan dibagian die casting, welding press $2 B$, warehouse, dan gensub unit. Berdasarkan hasil simple random sampling didapatkan jumlah responden sebanyak 99 tenaga kerja yang nantinya akan dijadikan responden. Penentuan jumlah sampel menggunakan rumus Taro Yamane. Pengumpulan data nantinya akan dilakukan dengan cara penyebaran kuesioner. Setelah data didapatkan, nantinya akan diolah menggunakan SPSS 22.0 dan jenis analisa yang digunakan adalah uji kendall tau-b untuk melihat hubungan antara sikap/ attitude, subjective norm dan perceived dengan safety behavior. Hasil dari analisis menggunakan SPSS 22.0 akan di lihatkan dalam bentuk tabel.

\section{HASIL dan PEMBAHASAN}

\section{Gambaran Umum Tempat Penelitian \\ PT. Abcd merupakan} perusahaan yang bergerak di bidang otomotif. Perusahaan ini mempunyai perusahaan induk yang membuat kerja sama antara PT. Abcd dengan PT. Abcd yang berada di Jepang. Status perusahan ini adalah perseroan terbatas dengan status investasi penanaman modal asing. Perusahaan ini didirikan pada tanggal 11 Juni 1971. PT. Abcd memiliki beberapa pabrik produksi di Jakarta. Lokasi dari perusahaan ini berada di Jalan Jakarta Utara. Perusahaan ini memiliki kapasitas produksi sebanyak 5.800.000 unit/ tahunnya. Perusahaan ini ada beberapa departemen produksi, die casting, welding press $2 B$, warehouse, dan gensub unit. Jumlah total pekerja di bagian tersebut ada 150 pekerja.

Perusahaan ini pernah meraih penghargaan Indonesia Best Brand Award 2012, Indonesia Most Admired Companies 2012, Top Brand 2013, Motorplus Award 2012, Indonesia's Most Favorite Youth Brand 2012, Word Of Mouth
Marketing 2012, Service Quality Award 2012, Otomotif Award 2012, Indonesia Most Favorable Brand In Social Media 2012, Indonesia's Most Favorite Women Brand 2012, Indonesia Motorbike Of The Year 2012, Motorcycle Of The Year 2012, HAI Youth Brand Award 2012, dan Indonesia Brand Champion 2012.

\section{Gambaran Umum Responden}

PT. Abcd memiliki pekerja dengan mayortas jenis kelamin laki-laki, pada penelitian ini tenaga kerja atau responden yang laki-laki berjumlah 95 tenaga kerja dan perempuan berjumlah 4 tenaga kerja. Mayoritas tenaga kerja di PT. Abcd memegang ijasah D1/D2/D3 karena rata-rata mereka berada di bidang produksi yang memerlukan keahlian khusus. Jumlah tenaga kerja yang lulusan S1 pada penelitian ini sebanyak 35 tenaga kerja dan 64 sisanya D1/D2/D3. sebgai besar tenaga kerja di PT. Abcd memiliki rentan umur yang dibilang masih muda yaitu 25-29 tahun dengan jumlah sebanyak 60 tenaga kerja $(60,6 \%)$.

a. Attitude Responden terhadap Perilaku Safety

Data yang diperoleh di PT. Abcd, sikap terhadap perilaku tenaga kerja didapatkan hasil bahwa mayoritas sikap/ attitude tenaga kerja tentang safety behavior sudah baik, dengan jumlah tenaga kerja sebanyak 79 tenaga kerja $(79.8 \%)$. Sedangkan tenaga kerja dengan sikap terhadap safety behavior yang tidak baik ada 20 tenaga kerja (20.2\%). Penilaian terhadap attitude tenaga kerja diukur dari sikap tenaga kerja pada saat menggunakan helm safety, sepatu safety dan earplug saat bekerja. Hal ini menunjukan ratarata tenaga kerja di PT. Abcd sudah memiliki sikap yang baik dan memiliki kesadaran akan pentingnya perilaku safety demi keselamatan dan keamanan mereka. Jumlah tenaga kerja yang memiliki 
sikap baik akan membuat terjadinya risiko kecelakaan kerja menjadi rendah, karena para tenaga kerja memiliki sikap yang baik. Contohnya apabila di perusahaan ada peraturan, maka mereka mempunyai sikap disiplin yang selalu menaati peraturan perusahaan seperti berperilaku safety saat bekerja. Dalam hal tenaga kerja memiliki pola pikir bahwa dengan bersikap baik saat bekerja akan membuat mereka menjadi aman dan selamat.
Keyakinan seseorang akan suatu tindakan akan berdampak baik apabila tindakannya itu baik dan akan berdampak buruk apabila perbuatannya buruk. Sama halnya dengan di tempat kerja, Apabila mereka yakin bahwa berperilaku safety dengan menggunakan APD akan membuat tenaga kerja aman dan selamat maka tenaga kerja akan selamat dan aman. Tetapi apabila mereka yakin bahwa tidak memakai APD itu aman, maka tenaga kerja tidak akan melakukannya (Ajzen, I., 2005).

Tabel 1. Distribusi Sikap terhadap Perilaku Safety pada Tenaga Kerja di PT. Abcd

\begin{tabular}{lcc}
\hline \multicolumn{1}{c}{ Attitude } & Jumlah & Persentase \\
\hline Kurang baik & 20 & $20.2 \%$ \\
\hline Baik & 79 & $79.8 \%$ \\
\hline Total & 99 & $100 \%$ \\
\hline
\end{tabular}

\section{b. Subjective Norm Responden terhadap Perilaku Safety}

Data yang diperoleh di PT. Abcd, didapatkan hasil bahwa mayoritas tenaga kerja tidak memiliki dukungan dari lingkungan sekitar yang baik, dengan jumlah sebanyak 73 tenaga kerja tidak memiliki dukungan dari lingkangan sekitar dan sebesar 26 tenaga kerja memiliki dukungan dari lingkungan sekitar yang baik. Bentuk pengukuran nilai dari subjective norm, dilihat dari seberapa banyak dukungan dari teman kerja kepada tenaga kerja lainnya untuk saling mengingatkan agar menggunakan alat pelindung diri seperti helm safety, sepatu safety, dan earplug. Hal ini menunjukkan bahwa mayoritas tenaga kerja di PT. Abcd tidak memiliki dukungan dari lingkungan sekitar atau teman kerja yang memenuhi/baik. Subjective norm pada penelitian ini diukur dari dukungan lingkungan sekitar seperti teman kerja supaya berperilaku safety saat bekerja.

Salah satu bentuk dukungan dari lingkungan kerja seperti selalu menegur teman kerja apabila ada yang tidak menggunakan alat pelindung diri saat bekerja. Apabila teman kerja memberikan dukungan antar sesama pekerja, maka risiko terjadinya kecelakaan kerja semakin rendah di PT. Abcd. Maka dari itu pengaruh lingkungan sekitar dapat membuat seseorang mempertimbangkan suatu perilaku (Ajzen, I. 2005). Norma subjektif dalam penelitian ini dilihat dari dukungan sosial dari lingkungan sekitar supaya berperilaku safety saat bekerja. Salah satu bentuk dukungan sosial yang dimaksud disini adalah pendapat teman kerja tentang penggunaan alat pelindung diri dan kepedulian teman kerja apabila ada yang tidak menggunakan alat pelindung diri saat bekerja. 
Tabel 2. Distribusi Subjective Norm terhadap Perilaku Safety pada tenaga kerja di PT. Abcd.

\begin{tabular}{lcc}
\hline Norma Subjektif & Jumlah (pekerja) & Persentase (\%) \\
\hline Kurang & 73 & $73.7 \%$ \\
\hline Baik & 26 & $26.3 \%$ \\
\hline Total & 99 & $100 \%$ \\
\hline
\end{tabular}

\section{c. Perceived Responden Terhadap Perilaku Safety}

Penelitian yang telah dilakukan di PT. Abcd didapatkan bahwa sebagian besar tenaga kerja sudah memiliki perceived yang memenuhi dalam berperilaku safety. Masing-masing jumlah sebesar 2 tenaga kerja dengan persentase $2 \%$ pada perceived yang tidak memenuhi dan pada perceived yang memenuhi sebanyak 97 tenaga kerja dengan persentase sebesar $98 \%$.

Hal ini menunjukkan bahwa mayoritas tenaga kerja di PT. Abcd sudah memiliki kesempatan yang cukup baik untuk berperilaku safety. Faktor yang digunkana untuk melihat perceived tenaga kerja dalam penelitian ini adalah dukungan sarana prasarana, jumlah alat pelindung diri yang sesuai jumlah tenaga kerja, dan kebijakan yang mengatur. Peraturan Menteri Tenaga Kerja dan Transmigrasi PER.08/MEN/VII/2010

menyebutkan bahwa setiap tempat kerja wajib menyediakan alat pelindung diri bagi tenaga kerjanya supaya mencegah terjadinya kecelakaan kerja yang tidak diinginkan.

Tabel 3. Distribusi Perceived terhadap Perilaku Safety pada Tenaga Kerja di PT.abcd.

\begin{tabular}{lcc}
\hline \multicolumn{1}{c}{ Perceived } & Jumlah (Pekerja) & Persentase (\%) \\
\hline Tidak Memenuhi & 2 & $2 \%$ \\
\hline Memenuhi & 97 & $98 \%$ \\
\hline Total & 99 & $100 \%$ \\
\hline
\end{tabular}

\section{Analisis Bivariat}

\section{a. Pengaruh Attitude terhadap Safety Behavior}

Data yang telah diperoleh pada penelitian di PT. Abcd disebutkan bahwa rata-rata tenaga kerja sudah bersikap baik dalam bekerja dan diikuti oleh niat yang baik juga dalam menerapkan perilaku safety. Tenaga kerja yang memiliki sikap yang kurang baik dan diikuti oleh niat berperilaku safety yang baik sebesar 12 tenaga kerja dengan persentase $60 \%$ dan tenaga kerja dengan sikap yang tidak baik diikuti oleh niat berperilaku safety yang kurang baik juga sebesar 8 tenaga kerja dengan persentase $20 \%$. Sedangkan pada tenaga kerja yang memiliki sikap baik diikuti oleh niat berperilaku safety baik sebesar 75 tenaga kerja dengan persentase $94,9 \%$ dan tenaga kerja yang memiliki sikap yang baik diikuti oleh biat berperilaku safety yang baik sebesar 4 tenaga kerja dengan persentase $5,1 \%$.

Hal ini menunjukkan bahwa tenaga kerja dengan sikap baik selalu diikuti oleh niat berperilaku safety yang baik juga. Berdasarkan uji statistik didapatkan hasil bahwa terdapat pengaruh antara niat dan attitude $(P=0,00022)$. Hal ini tidak sesuai dengan penelitian sebelumnya yang menyebutkan bahwa sikap belum pasti merubah perilaku tenaga kerja. Sikap hanya 
kecenderungan untuk bertindak (Tjipto, S dan Mohammad,. 2014).

$\begin{array}{llr}\text { Sikap } & \text { mempengaruhi } \\ \text { perilaku apabila seseorang }\end{array}$ mempercayai bahwa dia melakukan hal tersebut maka dia akan tahu hasilnya. Sikap juga dapat dilihat dari dampak yang ditimbulkan dari perilaku tersebut, bisa dampak positif atau dampak negatif bagi tenaga kerja (Ajzen, I., 2005).

Menurut Eka, D (2015) menyebutkan bahwa tenaga kerja yang tidak patuh menggunakan alat pelindung diri saat bekerja merupakan tenaga kerja yang memiliki sikap kurang baik. Hal ini sesuai dengan penelitian yang menyebutkan bahwa sikap sangat mempengaruhi perilaku tenaga kerja dalam menggunakan alat pelindung diri saat bekerja.

Penelitian beberapa ahli dan penelitian mengenai attitude atau sikap tenaga kerja terhadap perilaku safety menyimpulkan bahwa sikap tidak selamanya selalu mempengaruhi perilaku tenaga kerja.

Tabel 4. Pengaruh Attitude terhadap Safety Behavior

\begin{tabular}{|c|c|c|c|c|c|c|c|}
\hline \multirow{3}{*}{ Attitude } & \multicolumn{4}{|c|}{ Niat } & \multirow{2}{*}{\multicolumn{2}{|c|}{ Total }} & \multirow[t]{2}{*}{$P$-Value } \\
\hline & \multicolumn{2}{|c|}{ Safety } & \multicolumn{2}{|c|}{ Unsafety } & & & \\
\hline & $\mathbf{N}$ & $\%$ & $\mathbf{N}$ & $\%$ & $\mathbf{N}$ & $\%$ & \multirow{4}{*}{0.00022} \\
\hline Kurang baik & 12 & 60 & 8 & 40 & 20 & 100 & \\
\hline Baik & 75 & 94.9 & 4 & 5.1 & 79 & 100 & \\
\hline Total & 87 & 87.9 & 12 & 12.1 & 99 & 100 & \\
\hline
\end{tabular}

\section{b. Pengaruh Subjective Norm terhadap Safety Behavior}

Berdasarkan data yang telah didapatkan pada penelitian di PT. Abcd disebukan bahwa rata-rata tenaga kerja belum memiliki dukungan sosial dalam berperilaku safety yang baik. Tenaga kerja yang memiliki dukungan sosial yang baik diikuti oleh niat berperilaku safety yang baik sebesar 25 tenaga kerja dengan persentase 96,2\% dan tenaga kerja dengan dukungan sosial yang baik diikuti oleh niat berperilaku unsafety sebesar 1 tenaga kerja dengan persentase sebesar $3,8 \%$. Sedangkan tenaga kerja yang memiliki dukungan sosial yang tidak baik diikuti oleh niat berperilaju safety sebesar 62 tenaga kerja dengan persentase $84,9 \%$ dan tenaga kerja yang memiliki dukungan sosial tidak baik diikuti oleh niat berperilaku unsafety sebesar 11 tenaga kerja dengan persentase $15,1 \%$.

Hal ini menunjukkan bahwa mayoritas tenaga kerja memiliki dukungan sosial yang tidak baik dan diikuti oleh niat berperilaku safety. Berdasarkan uji statistik didapatkan hasil bahwa tidak adanya pengaruh antara subjective norm dengan niat safety behavior tenaga kerja $(P=0,175)$.

Hasil ini sesuai dengan penelitian sebelumnya yang menyebutkan bahwa subjective norm tidak ada pengaruh dalam perubahan perilaku tenaga kerja. Subjective norm hany menjadi menjadi pendukung mengenai pendapat bahwa berperilaku safety hanya bergantung pemikiran dan faktor internal dalam diri tenaga kerja (Yogatama, L., 2013).

Dorongan dari lingkungan sekitar tempat kerja seperti teman kerja dan atasan akan mempengaruhi atau tidak mempengaruhi tenaga kerja dalam melakukan niat berperilaku safety. Semakin banyak yang mempengaruhi individu maka akan semakin berpengaruh perubahan perilaku tersebut (Jogiyanto, HM., 2007). 
Perilaku terhadap dorongan

dari lingkungan sekitar atau lingkungan kerja pada tenaga kerja memiliki pengaruh yang berbedabeda. Tidak semua pengaruh dari lingkungan sekitar dapat membawa perubahan perilaku. Contoh dari pengaruh tersebut seperti pengalaman pribadi, budaya, dan media massa. (Notoatmodjo, S., 2003).

Menurut Ajzen, I (2005) norma subjektif merupakan sebuah dukungan atau masukan dari lingkungan sekitar seperti teman kerja untuk melakukan atau tidak melakukan sebuah perilaku safety.

Berdasarkan dari beberapa teori ahli dan beberapa penelitian sebelumnya maka dapat di tarik kesimpulan bahwa subjective norm tidak mempunyai pengaruh dalam mendorong perubahan perilaku safety dari tenaga kerja tersebut.

Tabel 5. Pengaruh Subjective Norm terhadap Safety Behavior

\begin{tabular}{|c|c|c|c|c|c|c|c|}
\hline \multirow{3}{*}{$\begin{array}{c}\text { Subjective } \\
\text { Norm }\end{array}$} & \multicolumn{4}{|c|}{ Niat } & \multicolumn{2}{|c|}{ Total } & \multirow{2}{*}{$\begin{array}{c}P- \\
\text { Value }\end{array}$} \\
\hline & \multicolumn{2}{|c|}{ Safety } & \multicolumn{2}{|c|}{ Unsafety } & & & \\
\hline & $\mathbf{N}$ & $\%$ & $\mathbf{N}$ & $\%$ & $\mathbf{N}$ & $\%$ & \multirow{4}{*}{0.175} \\
\hline Mendukung & 25 & 96.2 & 1 & 3.8 & 26 & 100 & \\
\hline Tidak Mendukung & 62 & 84.9 & 11 & 15.1 & 73 & 100 & \\
\hline Total & 87 & 87.9 & 12 & 12.1 & 99 & 100 & \\
\hline
\end{tabular}

\section{c. Pengaruh Perceived terhadap Safety Behavior}

Berdasarkan data yang telah didapatkan pada penelitian di PT. Abcd disebutkan bahwa rata-rata tenaga kerja memiliki perceived yang memenuhi dan diikuti dengan niat berperilaku safety yang baik dari tenaga kerja. Tenaga kerja yang memiliki perceived memenuhi yang diikuti oleh niat safety yang baik sebesar 86 tenaga kerja dengan persentase $88,7 \%$ dan tenaga kerja yang memiliki perceived memenuhi yang diikuti oleh niat bererilaku unsafety sebesar 11 tenaga kerja dengan persentase $11,3 \%$. Sedangkan pada perceived tidak memenuhi yang diikuti oleh niat berperilaku safety sebesar 1 tenaga kerja dengan persentase $50 \%$ dan tenaga kerja yang memiliki perceived tidak memenuhi yang diikuti oleh niat berperilaku unsafety sebesar 1 tenaga kerja dengan persentase $50 \%$. Pengukuran perceived pada penelitian ini menggunakan keterseidaan sarana prasarana, jumlah alat pelindung diri (helm safety, sepatu safety dan earplug) dan kebijakan yang mengatur sesuai dengan kebutuhan tenaga kerja.

Hal ini menunjukkan bahwa mayoritas tenaga kerja di PT. Abcd memiliki perceived yang memenuhi dan diikuti oleh niat berperilaku safety. Hasil uji statistik menyebutkan bawa tidak ada pengaruh antara perceived dengan niat safety behavior $(P=0,0288)$. Hasil ini sesuai dengan teori yang menyebutkan bahwa perceived dapat mempengaruhi niat tenaga kerja dalam melakukan suatu perilaku, tetapi apabila tenaga kerja tersebut memiliki persepsi yang baik dan akan menjadi sebaliknya apabila tenaga kerja tidak memiliki persepsi yang tidak baik (Ajzen, I., 2005).

Menurut Putu, D dan Gede I (2015) control perilaku dapat memprediksi terjadinya perubahan perilaku dari unsafety menjadi 
safety pada tenaga kerja. Semakin tinggi persepsi control perilaku tenaga kerja maka akan semakin mudah tenaga kerja tersebut berperilaku safety. Hal ini tidak sesuai dengan penelitian yang menyebutkan bahwa perilaku kontrok tidak mempengaruhi terjadinya perubahan perilaku pada tenaga kerja.

\section{Ketersdiaan}

sarana prasarana, alat pelindung diri telah diatur oleh peraturan sesuai dengan peraturan menteri tenaga kerja dan transmigrasi No. PER.08/MEN/VII/2010 bahwa setiap perusahaan atau tempat kerja wajib menyediakan alat pelindung diri atau APD bagi tenaga kerjanya supaya mereka dapat bekerja dengan aman dan selamat dan terhindar dari kecelakaan kerja pada tenaga kerja.
Dukungan sarana dan prasarana, jumlah alat pelindung diri, dan kebijakan pada tempat kerja merupaakn faktor yang dapat memepengaruhi suatu perilaku safety pada tenaga kerja. Hal ini karena tenaga kerja merasa mereka memiliki kesempatan dalam merubah perilaku dari unsafety menjadi safety. kenyamanan tenaga kerja dalam menggunakan alat pelindung diri juga menjadi faktor pendukung dalam peruabahan perilaku ( Yogatama, L., 2013).

Berdasarkan teori para ahli dan dari hasil penelitian sebelumnya dapat ditarik kesimpulan bahwa perceived tidak dapat merubah perilaku safety pada tenaga kerja. Karena ini hanya akan membuat tenaga kerja merasa memiliki kesempatan untuk memilih suatu perilaku.

Tabel 6. Pengaruh Perceived Terhadap Safety Behavior

\begin{tabular}{|c|c|c|c|c|c|c|c|}
\hline \multirow{3}{*}{ Perceived } & \multicolumn{4}{|c|}{ Niat } & \multirow{2}{*}{\multicolumn{2}{|c|}{ Total }} & \multirow{2}{*}{$\begin{array}{c}P- \\
\text { Value }\end{array}$} \\
\hline & \multicolumn{2}{|c|}{ Safety } & \multicolumn{2}{|c|}{ Unsafety } & & & \\
\hline & $\mathbf{N}$ & $\%$ & $\mathbf{N}$ & $\%$ & $\mathbf{N}$ & $\%$ & \multirow{4}{*}{0.228} \\
\hline Memenuhi & 86 & 88.7 & 11 & 11.3 & 97 & 100 & \\
\hline Tidak memenuhi & 1 & 50 & 1 & 50 & 2 & 100 & \\
\hline Total & 87 & 87.9 & 12 & 12.1 & 99 & 100 & \\
\hline
\end{tabular}

SIMPULAN

1. Gambaran Umum Responden

a. Mayoritas tenaga kerja telah memiliki attitude yang baik terhadap penggunaan alat pelindung diri

b. Mayoritas tenaga kerja tidak memiliki subjective norm/dukungan sosial dari lingkungan sekitar untuk menggunakan alat pelindung diri saat bekerja

c. Mayoritas tenaga kerja merasa terpenuhi kebutuhan akan sarana prasarana, jumlah alat pelindung diri dan kebijakan atau perceived.

2. Mayoritas kejadian unsafety behavior pada tenaga kerja dikarenakan perilaku pekerja yang kurang terhadap penggunaan APD.

3. Sikap pekerja di PT. Abcd mayoritas sudah baik dengan jumlah pekerja mencapai 79 pekerja (79.8\%)

4. Ada pengaruh Attitude atau sikap tenaga kerja terhadap niat berperilaku safety.

5. Tidak ada pengaruh subjective norm tenaga kerja terhadap niat berperilaku safety. 
6. Tidak ada pengaruh perceived tenaga kerja terhadap niat berperilaku safety.

7. Dilakukannya program penyuluhan terkait perilaku penggunaan alat pelindung diri (helm safety, sepatu safety, dan earplug) yang benar dan sesuai saat bekerja.

8. Dilakukannya pelatihan penggunaan alat pelindung diri saat bekerja atau saat terjadi bencana (kebakaran, gempa, dan lain-lain).

\section{DAFTAR PUSTAKA}

Ajzen I. 2005. Attitudes, Personality, and Behavior ( $2^{\text {nd }}$. Edition). England: Open University Press / McGraw-Hill.

Ayu, dkk., 2017. Penyuluhan Kesehatan Tentang Pentingnya Berperilaku Sehat Dan Selamat Dijalan Raya Pada SMK Farmasi Surabaya. Jurnal. Universitas Nahdatul Ulama Surabaya, 1(1),pp. 1619.

Ariwibowo, Raditya. 2013. Hubungan Antara Umur, Tingkat Pendidikan, pengetahuan, Sikap terhadap Prakrek Safety Riding Awareness Pada Pengendara Ojek Sepeda Motor Di Kecamatan Banyumanik, 2013. Jurnal Kesehatan Masyarakat. Volume 2 No.1.

BPJS Ketenagakerjaan. 2015. Angka Kasus Kecelakaan Kerja.

De Reamer. 1958. modern Safety Practice. New York.

Depkes RI. 2009. Menuju Masyarakat Sehat Yang Mandiri dan Berkeadilan. KEMENKES RI.

Eka, D., 2015. Perilaku Pemakaian Alat Pelindung Diri (APD). Universitas Jember, Fakultas Kesehatan Masyarakat.

Tresnaningsih. 2012. Penyakit Akibat Kerja Karena Pajanan logam Berat. Kemenkes RI.

ILO. 1989. Pencegahan Kecelakaan Kerja. Penerbit PT. Pustaka Binaman Pressindo. Jakarta

Izdihar, H., 2012. Motivasi Persepsi Petani Kentang Dataran Tinggi Dieng Terhadap Pestisida Organik Serta
Analisisnya Berasarkan Theory of Planned Behavior. Skripsi. Bogor, Institusi Pertanian Bogor

Metta Kartika. 2009. Analisa Faktor Penyebab Kecelakaan Lalu Lintas. Fakultas Kesehatan Masyarakat. Universitas Indonesia.

Jogiyanto, HM. 2007. Metodologi Penelitian Bisnis: Salah Kaprah dan Pengalaman-pengalaman. Cetkan Pertama. Yogyakarta. BPFE

Notoatmodjo, S. 2003. Pendidikan dan Perilaku Kesehatan. Rineka Cipta. Jakarta.

Notoatmodjo, S. 2010. Ilmu Perilaku Kesehatan. Rineka Cipta. Jakarta.

Notoatmodjo, S. 2014. Ilmu Perilaku Kesehatan. Jakarta, Rineke Cipta: 20-32

Oborne, David J. 1982. Ergonomic at Work. John Wiley and Sons Publishing Ltd: New York.

PERMENAKERTRANS No. PER.08/MEN/VII/2010 Undang-Undang Tentang Ketenagakerjaan. UU No. 1 Tahun 1970.

PT. Abcd. 2017. Laporan Hasil Patrol. Jakarta.

Putu, G dan Gede I., 2015. Sikap Norma Subjektif, dan Kontrol Perilaku Pada Implementasi Keselamatan Kerja: Dmpaknya Terhadap Intention To Comply. Jurnal Universitas Udayana, 4(4), pp 243-264. 
Reason J. 1995. A System Approach to Organizational Error. Ergonomics, 38(8). 1708/1721.

Reason J. 1997. Managing the Risk of Organizational Accidents. Ashgate Publishing.

Retnani, D dan Denny., 2013. Analisis Pengaruh Activator Dan Consequence Terhadap Safe Behavior Pada Tenaga Kerja Di PT. Pupuk Kaltim Tahun 2013. Journal of Occupational Safety and Health, 2(2),pp 119-129.

Santoso dan Sherly,. 2012. pengaruh Profitabilitas, Financial Leverage, Dividen, Ukuran Perusahaan, Kepemilikan Institusional, dan Kelompok
Usaha Terhadap Perataan Laba Studi Kasus Pada Perusahaan Non-Finansial Yang Terdaftar Di Bei. Jurnal Unissula, 1(1), pp 185-213

Tjipto, S dan Mohammad. 2014. Hubungan Antara Knowledge, Attitude, Practice Safe Behavior Pekerja Dalam Upaya Menegakkan Keselamatan dan Kesehatan Kerja. Journal Universitas Airlangga, 3(1), pp82-93.

Undang-Undang No. 13 Tahun 2003 Bab I Pasal 1 Ayat 2 Tentang Ketenagakerjaan Jakarta

WHO. 2011. A Decade Of Action For Road Safety: A Brief Planning Document. 